\title{
Correction to: Examining Reservoir Sedimentation and Estimating Dam Stockpiling Limit Utilizing Bathymetry Overview: A Contextual Investigation of Abrajit Dam, North Gojjam Sub-basin, Blue Nile basin, Ethiopia
}

\author{
Mekash Shiferaw $^{1}$ (D) Roman Abebe $^{1}$ \\ C Indian Society of Remote Sensing 2020
}

Correction to: Journal of the Indian Society of Remote Sensing (September 2020) 48(9):1313-1323 https://doi.org/10.1007/s12524-020-01159-8

The article [Examining Reservoir Sedimentation and Estimating Dam Stockpiling Limit Utilizing Bathymetry Overview: A Contextual Investigation of Abrajit Dam, North Gojjam Sub-basin, Blue Nile basin, Ethiopia], written by [Mekash Shiferaw and Roman Abebe], was originally published electronically on the publisher's internet portal (currently SpringerLink) on [5th September 2020] with open access. With the author(s)' decision to step back from Open Choice, the copyright of the article changed on [18th October 2020] to (C) [Indian Society of Remote Sensing] [2020] and the article is forthwith distributed under the terms of copyright.

The original article has been corrected.
The original article can be found online at https:// doi.org/10.1007/s12524-020-01159-8.

\section{Mekash Shiferaw}

mekahydro@gmail.com

1 Department of Hydraulic and Water Resources Engineering, Debre Tabor University, Debre Tabor, Ethiopia 